\title{
Diabetes and the NHS in England in November 2016
}

\author{
JONATHAN VALABHJI
}

The Five Year Forward View (FYFV) was published in October 2014. ${ }^{1}$ It set out a broad strategy to promote long-term sustainability in the NHS, whilst continuing to drive up clinical quality. It articulated the need to act to address a forecast shortfall in funding for the NHS of around $\mathrm{f30}$ billion per year by 2020, without a real terms increase in spend on healthcare.

There was to be a focus on prevention to manage demand, and on the adoption of innovative technology to support more efficient healthcare.

The FYFV prioritised six clinical areas: diabetes, maternity services, cancer, mental health, dementia and learning disabilities. In response to the challenge set out in the FYFV, the Department of Health, Public Health England, Diabetes UK and NHS England worked in partnership to establish the NHS Diabetes Programme. The Programme includes three key workstreams:

1. The Healthier You: NHS Diabetes Prevention Programme, which is focused on prevention of type 2 diabetes in those at risk.

2. A Diabetes Treatment and Care Workstream, which is focused on improving treatment and care for the 2.8 million adults and children with a diagnosis of type 1 or type 2 diabetes, with a specific focus on secondary prevention.

3. A Digital Diabetes Workstream which is focused on harnessing technology to support prevention of type 2 diabetes and selfcare in people with type 1 and type 2 diabetes.

\section{Healthier You: NHS Diabetes Prevention Programme}

With two-thirds of the adult population of England now overweight or obese, ${ }^{2}$ the future burden of obesity and its associated conditions, such as type 2 diabetes, on NHS resources will be significant unless we take action. Randomised controlled trials ${ }^{3-7}$ had already demonstrated that behavioural interventions directed to those with impaired glucose tolerance to cause weight loss, increased physical activity and better quality nutrition reduced the cumulative incidence of type 2 diabetes by up to 58\%.5 A national evidence-based type 2 diabetes prevention programme 'Healthier You: the NHS Diabetes Prevention Programme' has therefore been launched for those at risk, to both tackle the burgeoning consequences of obe-

Address for correspondence: Professor Jonathan Valabhji National Clinical Director for Diabetes and Obesity, NHS England Zone B, 6th Floor, Skipton House, 80 London Road, London,

SE1 6LH, UK

Tel: $+44(0) 1138251692$

E-mail: jonathan.valabhji@imperial.nhs.uk

Br J Diabetes 2016;16:151-153

http://dx.doi.org/10.15277/bjd.2016.103 sity and type 2 diabetes and to support a more general shift in the NHS towards the prevention agenda.

The programme was launched by Simon Stevens, CEO of NHS England, at the Diabetes UK Annual Professional Conference in March 2015. Over the first financial year (2015/16) we:

- Worked with seven demonstrator sites to test a diabetes prevention pathway across different environments: urban and rural, socioeconomically deprived areas and areas less deprived, areas with high proportions of people of South Asian ethnicity, and an area with high proportions of people of African and Caribbean ethnicity (given the higher risk and prevalence of type 2 diabetes in people of South Asian, African and Caribbean origins within the $\mathrm{UK}^{8}$ ).

- Commissioned an evidence review of real-world translations of the original diabetes prevention randomised controlled trials. ${ }^{9}$

- Established an expert reference group which translated the commissioned evidence review, NICE guidelines ${ }^{10}$ and the group's own knowledge and experience to derive the first iteration of a national service specification for a diabetes prevention programme.

- Consulted on a draft national service specification through a public consultation, a consultation with potential providers and through a Diabetes UK-sponsored user group which was established. In addition, a testimonial day was held so that researchers in the field could input into the development of the final specification.

- Used the resulting national service specification as the basis for a national procurement exercise. The specification required intensive group-based face-to-face interventions involving at least 13 sessions over at least 9 months, constituting at least 16 hours of intervention time, and the objective of the national procurement exercise was to appoint providers who had the capability to deliver the specified intervention anywhere across England. Following the national procurement exercise, four providers were appointed to a national framework in March 2016.

- In parallel to the national procurement exercise, a call went out for expressions of interest from local health economies to become the first wave of sites to join the programme during the first phase of national roll-out in financial year 2016/17. There was significant interest with around three-quarters of Clinical Commissioning Groups (CCGs) and local authorities expressing interest, and 27 first wave sites covering nearly half of England were appointed on the basis of the infrastructure that was already in place to identify and refer those already known to be at high risk of type 2 diabetes (those with non-diabetic hyperglycaemia: $\mathrm{HbA}_{1 \mathrm{c}} 42-47 \mathrm{mmol} / \mathrm{mol}$ or fasting glucose 5.5-6.9 $\mathrm{mmol} / \mathrm{L})$. 
Each of the 27 local health economies that were chosen for the first wave has now had the opportunity to choose from the four providers on the national framework and referrals onto the national programme began in June. By the end of September around 3,700 people had been referred to the new national programme, with the volume of referrals expected to increase rapidly from October as more local health economies begin to make referrals.

We expect to recruit up to 20,000 people onto the programme this financial year and expressions of interest from potential second wave local health economies, to come on line from April 2017, have been received. Geographically, by the second wave of roll-out, around $75 \%$ of England will be covered and, by third wave, $100 \%$. At steady state, we expect to deliver 100,000 interventions per year.

Payments to providers are based on retention of the individual in the programme. As this is a 9-month long intervention, there are five stage payments which creates an incentive for providers to retain individuals on programmes. Data collected will look at attendance, demographics and reductions in weight and $\mathrm{HbA}_{1 \mathrm{c}}$.

Currently, the National Diabetes Audit (NDA) captures those with a coded diagnosis of diabetes. ${ }^{11}$ There is an intention, with planned pilots, to expand that data extraction to also include anyone with a coded diagnosis that is consistent with non-diabetic hyperglycaemia. There are also new codes for referral into, attendance at and completion of the diabetes prevention programme. While NDA reports have to date evaluated data cross-sectionally, individuals, via their NHS number, can be followed longitudinally. Over time, therefore, this data capture will allow comparison of those with non-diabetic hyperglycaemia who have attended the programme with those who have not attended, with a view to assessing the impact of the intervention in the long term on diabetes incidence and even the subsequent development of diabetes complications.

Furthermore, the National Institute for Health Research has put out a dedicated call for evaluation of the programme, the deadline for which was in June. They are expected to award a contract for long-term evaluation of the programme in the near future.

\section{Diabetes Treatment and Care Workstream}

The themes of the Diabetes Treatment and Care Workstream were identified through joint work between the Department of Health, Diabetes UK and NHS England and are based on elements of care and interventions for those with type 1 and type 2 diabetes for which evidence could be cited for not only improving quality of care, but also for potential returns on investment. The four selected themes are:

- Achievement of the treatment targets (for $\mathrm{HbA}_{1 c}$, blood pressure and cholesterol in adults and just $\mathrm{HbA}_{1 \mathrm{c}}$ in children) and tackling variation around that achievement ${ }^{12}$ in order to prevent onset of complications. It should be noted that the aim is not to shift the entire diabetes population distributions for $\mathrm{HbA}_{1 \mathrm{c}}$ and blood pressure, as this would have the potential to put those in the lower part of those distributions at risk of hypoglycaemia and postural hypotension. The aim is for those CCGs or practices below the median level of achievement of all three treatment targets to achieve the median for 2014/15.
- Attendance at structured education: cases were made for potential returns on investment for structured education programmes for those with type $1^{13}$ and type $2^{14,15}$ diabetes.

- Multidisciplinary diabetic foot care, and more specifically the existence of and sufficient capacity within a multidisciplinary foot service. Multidisciplinary diabetic foot care has been shown to reduce amputations by up to $50 \%,{ }^{16}$ and a strong economic case has been made. ${ }^{17}$ The latest National Diabetes Inpatient Audit Report suggests that $31 \%$ of hospital sites do not have a multidisciplinary diabetic foot service. ${ }^{18}$

- Inpatient care, and more specifically the existence of and sufficient capacity within a diabetes inpatient specialist nurse service. Again, a strong economic case has been made. ${ }^{19}$ The latest National Diabetes Inpatient Audit Report suggests that onethird of hospital sites have no diabetes inpatient specialist nurse available. ${ }^{18}$

The CCG Improvement and Assessment Framework (CCG IAF) was launched this year. ${ }^{20}$ There are two metrics to assess diabetes in the CCG IAF: achievement of the treatment targets and attendance at structured education. As part of this, each of the 209 CCGs across England will be rated on their overall diabetes care, based on a composite of the two metrics for diabetes. An independent panel chaired by Diabetes UK Chief Executive, Chris Askew, will approve the assessment.

The NHS England Planning Guidance, published in October 2016, stated that $f 40$ million per year for the next two financial years would be available to support the four diabetes treatment and care themes. ${ }^{21}$ Rather than allocation on a fair-share basis, CCGs will be invited to bid for funds. Strength of bids, as well as outputs from the CCG IAF for the first two of the four themes, will inform the allocation process. The bidding process will open shortly, and providers of diabetes care should be aware that their local CCGs may require input and support in assessing local need and completing applications.

\section{Digital Programme}

The two current diabetes digital priorities are around The Healthier You: Diabetes Prevention Programme and the development of a new package of online support for younger adults with type 1 diabetes:

- Simon Stevens announced the launch of our Digital Diabetes Prevention programme at the NHS Expo Conference in September 2016. Data modelled from the Health Survey for England by Public Health England suggest that there are approximately five million people in England with non-diabetic hyperglycaemia, 22 yet at full roll-out the Diabetes Prevention Programme will deliver only 100,000 interventions per year. Our experience over many years of delivery of structured education to those with type 1 or type 2 diabetes is that those of working age have difficulty attending. The concept of a digital mode of delivery of diabetes prevention is therefore an attractive one. However, evidence of clinical effectiveness is lacking for digital delivery. We will therefore procure an evaluation partner to test a number of digital diabetes prevention delivery systems in the realworld environment.

- The type 1 diabetes digital offer connects to NHS England's 
focus on technology and innovation, particularly harnessing digital resources for delivery of healthcare. The aim is to provide younger adults with type 1 diabetes a digital offer that would provide support, signposting, information and education, and also potentially a tool for communication and health transactions. Diabetes UK and NHS digital teams have been working closely together to develop the blueprint of the offer, which is still in development.

\section{Consistency within NHS England's other work programmes}

\section{Sustainability and Transformation Plans}

New geographical areas called footprints, which draw together CCGs and local authorities, commissioners and providers, have now been defined across England. Each of the 44 must produce a Sustainability and Transformation Plan (STP). Aide-mémoires have been produced for use by these collaboratives for each of the major priority areas, including diabetes. ${ }^{23}$ To promote consistency, the 'Aide-mémoire: diabetes' emphasises the importance of:

- referral pathways to support the Healthier You: NHS Diabetes Prevention Programme;

- achievement of treatment targets;

- attendance at structured education;

- multidisciplinary diabetes footcare;

- diabetes inpatient care.

\section{RightCare Programme}

An independent resource is available via the RightCare Programme, which looks to define optimum care for best value. ${ }^{24}$ We are currently working with the RightCare Programme team to define optimum clinical pathways for the management of type 1 and type 2 diabetes.

\section{Conclusions}

The importance of addressing the challenge posed by diabetes has been recognised in the FYFV and there are opportunities to improve the quality of care and outcomes for people with type 1 and type 2 diabetes, as well as to prevent or delay the onset of type 2 diabetes in those at risk. Specialist diabetologists are uniquely placed to advise and work constructively with their CCGs and STPs to deliver what is required, and to assist in the preparation of bids for additional funding in the areas outlined.

\section{References}

1. NHS England. Five Year Forward View. 2014. https://www.england. nhs.uk/ wp-content/uploads/2014/10/5yfv-web.pdf (last accessed 4 Nov 2016).

2. Public Health England. Adult Obesity Slide Set (updated April 2016). https://www.noo.org.uk/gsf.php5?f=14605\&fv=22122 (last accessed 4 Nov 2016).

3. Pan XR, Li GW, Hu YH, et al. Effects of diet and exercise in preventing NIDDM in people with impaired glucose tolerance. The Da Qing IGT and Diabetes Study. Diabetes Care 1997;20:537-44. https://doi.org/10.2337/diacare.20.4.537

4. Tuomilehto J, Lindstrom J, Eriksson JG, et al. Prevention of type 2 diabetes mellitus by changes in lifestyle among subjects with impaired glucose tolerance. N Engl J Med 2001;344:1343-50. https://doi.org/10.1056/NEJM200105033441801

5. Diabetes Prevention Program Research Group. Reduction in the incidence of type 2 diabetes with lifestyle intervention or metformin. N Engl J Med
2002;346:393-403. https://doi.org/10.1056/NEJMoa012512

6. Kosaka K, Noda M, Kuzuya T. Prevention of type 2 diabetes by lifestyle intervention: a Japanese trial in IGT males. Diabetes Res Clin Pract 2005;67:152-62. https://doi.org/10.1016/j.diabres.2004.06.010

7. Ramachandran A, Snehalatha C, Mary S, et al. The Indian Diabetes Prevention Programme shows that lifestyle modification and metformin prevent type 2 diabetes in Asian Indian subjects with impaired glucose tolerance (IDPP-1). Diabetologia 2006:49:289-97.

https://doi.org/10.1007/s00125-005-0097-z

8. Public Health England. Adult obesity and type 2 diabetes. https:// www.gov.uk/government/uploads/system/uploads/attachment_data/file/33 8934/Adult_obesity_and_type_2_diabetes.pdf (last accessed 4 Nov 2016).

9. Public Health England. A systematic review and meta-analysis assessing the effectiveness of pragmatic lifestyle interventions for the prevention of type 2 diabetes mellitus in routine practice. 2015. https://www. gov.uk/government/uploads/system/uploads/attachment_data/file/456147/PHE Evidence_Review_of_diabetes_prevention_programmes-_FINAL.pdf (last accessed 4 Nov 2016).

10. National Institute for Health and Care Excellence. Type 2 diabetes: prevention in people at high risk. https://www.nice.org.uk/guidance/ ph38/resources/type-2-diabetes-prevention-in-people-at-high-risk-1996304192197 (last accessed 4 Nov 2016).

11. NHS Digital. National Diabetes Audit. http://content.digital.nhs.uk/nda (last accessed 4 Nov 2016).

12. NHS Digital. National Diabetes Audit - 2013-2014 and 2014-2015: Report 1. Care Processes and Treatment Targets. 2016. http:// content. digital. nhs. uk/searchcatalogue? productid $=20155 \& q=\% 22 \mathrm{Na}-$ tional+diabetes+audit\%22\&sort=Relevance \&size=10\&page=1\#top (last accessed 4 Nov 2016)

13. Shearer A, Baqust A, Sanderson D, et al. Cost-effectiveness of flexible intensive insulin management to enable dietary freedom in people with type 1 diabetes in the UK. Diabet Med 2004;21:46-7. https://doi.org/10.1111/j.1464-5491.2004.01183.x

14. Deakin T. The diabetes pandemic: is structured education the solution or an unnecessary expense? Practical Diabetes 2011;28:8. https://doi.org/10.1002/pdi.1635

15. Hayes A, Leal J, Gray AM, et al. UKPDS Outcomes Model 2: a new version of a model to simulate lifetime health outcomes of patients with type 2 diabetes mellitus using data from the 30 year UKPDS 82. Diabetologia 2013;56:1925-33. http://dx.doi.org/10.1007/s00125-013-2940-y

16. Edmonds ME, Blundell MP, Morris ME, Thomas EM, Cotton LT, Watkins PJ. Improved survival of the diabetic foot: the role of a specialized foot clinic Q J Med 1986;60:763-71.

17. Kerr M. Foot care for people with diabetes: the economic case for change. 2012. https://www. diabetes.org.uk/Documents/nhs-diabetes/ footcare/footcare-for-people-with-diabetes.pdf (last accessed 4 Nov 2016).

18. NHS Digital. National Diabetes Inpatient Audit (NaDIA) - 2015. 2016. http://content.digital.nhs.uk/catalogue/PUB20206/nati-diab-inp-audi-15nat-rep.pdf (last accessed 4 Nov 2016).

19. Kerr M. Inpatient care for people with diabetes: the economic case for change. 2011. https://www. diabetes.org.uk/upload/News/Inpatient\%20 Care\%20for\%20People\%20with\%20Diabetes\%20\%20The\%20Economic \%20Case \%20for\%20Change\%20Nov\%202011.pdf (last accessed 4 Nov 2016).

20. NHS England. CCG Improvement and Assessment Framework 2016/17. 2016. https://www.england.nhs.uk/commissioning/wp-content/uploads/ sites/12/2016/03/ccg-iaf-mar16.pdf (last accessed 4 Nov 2016).

21. NHS England. NHS Operational Planning and Contracting Guidance 2017 2019. 2016. https://www.england.nhs.uk/wp-content/uploads/ 2016/09/ NHS-operational-planning-guidance-201617-201819.pdf (last accessed 4 Nov 2016).

22. Public Health England. NHS Diabetes Prevention Programme (NHS DPP) Non-diabetic hyperglycaemia. 2015. https://www.gov.uk/government/ uploads/system/uploads/attachment_data/file/456149/Non_diabetic_hyperglycaemia.pdf (last accessed 4 Nov 2016).

23. NHS England. STP aide-mémoire: diabetes. 2016. https://www.england. nhs.uk/wp-content/uploads/2016/05/stp-aide-memoire-diabetes.pdf (last accessed 4 Nov 2016).

24. NHS England. NHS RightCare Programme. 2016. https://www.england. nhs.uk/rightcare/programme/ (last accessed 4 Nov 2016) 